\title{
LA PRODUCCIÓN DE TRIGO EN ESPAÑA \\ EN EL ÚLTIMO TERCIO DEL SIGLO XIX. UNA COMPARACIÓN INTERNACIONAL
}

\author{
RAFAEL BARQUÍN GIL \\ Universidad de Burgos
}

\section{RESUMEN}

El propósito del artículo es presentar la evolución de la producción triguera de España en la última década del siglo xIx. Para ello, se evalúan varias informaciones del periodo, y en particular dos de ellas: los avances estadísticos realizados por los ingenieros agrónomos provinciales en la década de los ochenta, y la estadistica sobre consumo de cereales del Ministerio de Fomento de 1868. La principal conclusión que se deriva de esa investigación es que el consumo y la producción de trigo entre 1868 y 1890 fueron similares a los del período 1890-1896, lo que asemeja el caso español al italiano. Probablemente, el Arancel Cánovas tuvo un poderoso efecto en el incremento del autoconsumo de los campesinos cerealícolas.

\section{ABSTRACT}

The aim of this paper is to show the evolution of Spanish wheat output in the last decades of XXX century. The paper evaluates both the advances in statistical methods achieved by provincial agricultural scientists in the 80's, and the statistic consumption data published by the Ministry of Public Works in 1868. The main conclusion is that consumption and output of wheat between 1868 and 1890 were similar to those obtained for the period 1890-1896. This suggest that the Spanish and Italian cereal sectors behaved quite alike. The paper also proves that the tariff aproved by Cánovas had a powerful effect on the wheat pattern of consumption of the Spanish peasantry.

$N$ de E.: Fecha de recepción del artículo en la Revista de Historia Económica: junio, 2000.

Fecha de aprobación por el Consejo de Redacción: noviembre, 2001. 


\section{INTRODUCCIÓN}

Los años a partir de los cuales disponemos de información fiable sobre la producción de trigo en Europa Occidental se encuentran muy alejados unos de otros. Si nos guiamos por las estadísticas recopiladas por Mitchell -quien se apoya en fuentes oficiales-, los primeros registros nacionales de cosechas en Europa Occidental se habrían efectuado en Francia desde 1815, y los últimos en España desde $1890^{1}$. Esta última es la presentada por la Junta Consultiva Agronómica, un organismo dependiente del Ministerio de Fomento, que el Grupo de Estudios de Historia Rural ha criticado, sintetizado y reeditado en varias ocasiones ${ }^{2}$. Este trabajo pretende atacar esta ausencia de información desde diversos frentes. En primer lugar, trataremos de percibir cómo evolucionó la producción del trigo en otros países. Luego veremos algunas informaciones sobre la producción española de trigo en el período 1882-1890. Por último, haremos algunas hipótesis sobre la evolución del consumo de trigo con anterioridad a esos años.

\section{UNA COMPARACIÓN INTERNACIONAL}

El gráfico 1 recoge, en forma de números-índice, el consumo aparente de trigo por habitante en Francia, Italia y Portugal desde 1850 hasta 1914. Por consumo aparente se entiende la suma de la producción y las importaciones netas; es decir, se ha restado de cada una de estas magnitudes brutas la sementera y las exportaciones. Lo segundo no comporta mayor dificultad de la de emplear números negativos. Pero la cuantía de la sementera es mucho menos precisa; no sólo resulta comprometido asignar un factor simiente a cada sistema agrícola; además no hay ningún motivo para suponer que el mismo se mantuviera estable a lo largo del período. A partir de los trabajos de Clout para Francia, Percosolido para Italia, y Lains para Portugal, se han estimado esos factores en 1:9, 1:8 y 1:7, respectivamente ${ }^{3}$. $\mathrm{Si}$, como parece lógico, a largo plazo se produjo un aumento en la productividad de la tierra, cabe pensar que los niveles de consumo de los primeros años estén algo sobrevalorados con relación a los últimos.

B. R. Mitchell (1992).

2 La más completa en GEHR (1991).

${ }^{3}$ H. D. Clout (1983), pp. 148-149; G. Percosolido (1994), p. 148; P. Lains (1990), pp. 10-13. Las estimaciones de M. K. Bennett (1935) para los tres países en la década 1885-1894 son 1:9, 1:8,7 y 1:7,6. Para España sería 1:5,8; pero existen reservas fundadas sobre la credibilidad de las cifras manejadas. Ver más abajo nota 19. 


\section{GRÁFICO 1}

\section{Consumo de trigo per cápita}

medias móviles de 5 años $(1905-1914=100)$

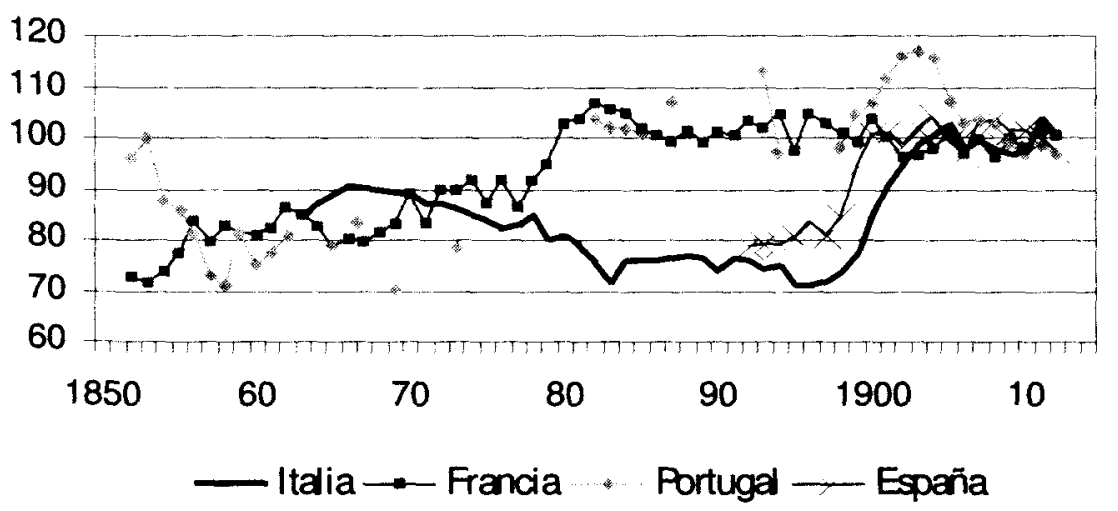

En realidad, las mismas cifras de producción son discutibles. Las más fiables son las francesas. Las de Italia — que no arrancan hasta 1861han sido criticadas por Federico; en esencia, supone que las primeras magnitudes deberían ser menores, asunto de cierta trascendencia sobre el que enseguida volveremos ${ }^{4}$. La mayor parte de las de Portugal han sido obtenidas recientemente por Lains y Silveira a partir de cierta información oficial $^{5}$. No obstante, esta labor de reconstrucción no ha podido completarse en todos los años, de forma que hay varias lagunas, especialmente en la década de los setenta. Puede que estemos lejos de la exactitud, pero tampoco ésa era nuestra meta. Lo único a lo que aspira el gráfico es a dar una idea de la tendencia del consumo per cápita de trigo en esas tres naciones. $Y$, en este sentido, los errores estadísticos o la utilización de un factor simiente u otro apenas alteran la imagen. La evolución del consumo per cápita de trigo es creciente en los tres casos; pero resultan muy llamativas las diferencias existentes entre cada uno de ellos. En Francia el consumo per cápita creció hasta comienzos de los ochenta, estabilizándose desde entonces. En Italia fue cayendo muy suavemente desde 1865 hasta 1900, para crecer fuertemente con el cambio de siglo, estabilizándose desde 1905 hasta 1914. No obstante, si como parece las cosechas de los

\footnotetext{
G. Federico (1982), pp. 100-110.

5 P. Lains y P. Silveira (1998).
} 
primeros treinta años son algo menores, sería más exacto suponer que el consumo per cápita de trigo se mantuvo estable a lo largo de la segunda mitad del siglo XIX. En Portugal, la serie carece de tendencia en la década de los cincuenta y sesenta (aunque los primeros datos son muy elevados); pero tras la laguna de los setenta, se percibe un consumo muy elevado en los ochenta, que se mantendrá hasta finales de siglo.

No es fácil explicar estas tendencias. Parece claro que diferentes factores propiciaron cambios en la dieta en distintas fechas ${ }^{6}$. En Francia el elemento decisivo pudo haber sido la tendencia decreciente de la elasticidad renta del pan de trigo conforme aumentaba el nivel de vida. Las importaciones de trigo, especialmente grandes a partir de 1878, propiciaron la aplicación de aranceles proteccionistas; en particular, el de 1887, que supuso una elevación de la tarifa sobre los granos extranjeros desde 60 céntimos de franco por quintal métrico hasta los 5 francos. Esta política permitió la supervivencia de muchas pequeñas explotaciones cerealícolas; pero no parece haber estimulado un mayor consumo ${ }^{7}$. Podemos suponer que la demanda del trigo era relativamente insensible a las variaciones del precio; y que la elasticidad renta del pan de trigo también era, por entonces, próxima a $0^{8}$.

Estas circunstancias no se repetían en Portugal, un país mucho más pobre y con una dieta mucho más volcada hacia el consumo de otros cereales ${ }^{9}$. Así, Pedro Lains estima la elasticidad renta del trigo para Portugal en 1850 y 1900 en 1,40 y 1,29 , respectivamente, lo que debe ser atribuido

6 Un estudio para toda Europa Occidental puede encontrarse en M. K. Bennett (1935).

7 M. S. Smith (1980), pp. 197-215.

${ }^{8}$ M. Levy-Leboyer y F. Bourguignon (1990), pp. 152-159, calculan, entre otras, la elasticidad parcial del consumo de bienes agrícolas (concepto equivalente al de elasticidad precio de la demanda), y la elasticidad total de dicho consumo, que incluye el efecto renta generado por los mayores ingresos de los campesinos ante una elevación del precio. Para el último de los períodos analizados, 1887-1913, la primera es igual a $-0,612$, lo que sugiere que variaciones en el precio de los bienes agrícolas provocarian una disminución moderada de su consumo. La segunda es igual a $-0,442$, lo que indica que el efecto renta (mayores ingresos de los campesinos y, consecuentemente, mayor consumo de éstos) no compensó la caída del consumo de los grupos no productores. Sin embargo, estas elasticidades en el período $1860-1886$ fueron de $-0,424$ y $-0,088$. Es decir; la elasticidad de la demanda se hace más baja y, sobre todo, el efecto renta de los campesinos está cerca de compensar el efecto precio. No obstante, el valor argumentativo de estos cálculos es muy discutible, pues están referidos al conjunto de productos agrícolas, y no específicamente al trigo.

9 D. Justino (1988-1989, vol. II, p. 12) estima que en 1865 cada portugués residente en el continente consumía al año una media de $183 \mathrm{kgs}$ de maíz, $66 \mathrm{kgs}$ de centeno y 50 kgs de patatas por cada $81 \mathrm{kgs}$ de trigo. 
permaneció estancado en el último tercio del siglo XIX. Esta idea constituye el argumento central del presente artículo. Pero para probar esta hipótesis necesitamos saber, al menos, cuánto trigo se cosechó y consumió en España en los años ochenta. No contamos con las mejores informaciones para averiguarlo; pero creo que algo se puede hacer con lo que tenemos.

\section{LOS AVANCES ESTADÍSTICOS DE LA DÉCADA DE LOS OCHENTA}

El trabajo efectuado desde 1890 por la Junta Consultiva Agronómica no partió de cero. Durante la década anterior los funcionarios del Servicio Agronómico, dependiente del Ministerio de Fomento, elaboraron diversos informes sobre los rendimientos, la superficie y la producción de cereales, vino y aceite. En realidad, durante la segunda mitad del siglo muchas veces se hicieron estimaciones sobre la producción de trigo, normalmente basadas en interrogatorios remitidos a las autoridades municipales desde los Gobiernos Civiles. En 1857 esta actuación permitió efectuar el primer cómputo nacional de cosechas desde el reinado de Fernando VII, si bien, como veremos, los resultados son harto discutibles. En esta ocasión, y en otras, la información finalmente recibida en el Ministerio de Fomento fue demasiado parca como para elaborar estimaciones nacionales. Esto puede explicar el enorme desconocimiento que tenemos sobre las encuestas efectuadas a finales de los cincuenta y durante los sesenta. De la de 1872 nos quedan 23 informes provinciales, que, por cierto, incluyen memorias explicativas sobre el estado de la agricultura en cada provincia. Sólo la creación de un cuerpo de Ingenieros Agrónomos Provinciales en 1879 parece haber supuesto una verdadera novedad en los métodos de cálculo. Los estudios conducentes a la obtención del título habían sido aprobados desde mucho antes, en 1855; e incluían los destinados a la elaboración de estadísticas agrícolas. Así, el Ministerio de Fomento dispuso de un instrumento con el que conocer el estado y los problemas del sector primario en España. $\mathrm{Si}$, pese a ello, en los primeros años se conformó con requerir estados sobre la cosecha anual, debió ser por pura inercia ${ }^{16}$.

${ }^{16}$ Hubo otros intentos, no muy afortunados, por conocer la producción de trigo en España. Quizás el más amplio haya sido el realizado por la compañía de ferrocarriles Norte sobre las producciones y rendimientos en las 19 provincias (Madrid, Ávila, Segovia, Zamora, Salamanca, Valladolid, Palencia, León, Santander, Burgos, Álava, Logroño, Vizcaya, Navarra, Zaragoza, Huesca, Lérida, Tarragona y Barcelona) en las que tenía líneas en los años 
Pues lo cierto es que en los primeros informes, remitidos entre 1882 y 1886, sólo se indica la cosecha provincial. Aunque pudiera haber otros procedimientos, lo más razonable es suponer que para hallarla los ingenieros agrónomos hicieron en esos años lo mismo que se hizo desde 1890: estimar el rendimiento provincial como la media del de varias localidades a las que se consideraba representativas, y multiplicarlo por la superficie derivada de los amillaramientos y, en su caso, el catastro. De hecho, los informes del siguiente lustro, 1886-1890, recogen información sobre la producción y los rendimientos en cada provincia (de los que, obviamente, se deriva la superficie sembrada). Hay, pues, una presunción de continuidad en el trabajo estadístico de la década de los ochenta con relación a la de los noventa, que arranca del hecho de que fue elaborado por las mismas personas ${ }^{17}$.

Conocemos el resultado nacional de esas estimaciones; pero casi todo el detalle de la información se ha perdido. En concreto, sobre el quinquenio 1882-1886 sabemos dos cosas: $1 .^{\circ}$ cuánto trigo se cosechó en todo el país (excluidas las islas Baleares y Canarias) en cada uno de esos años: 22.199, $26.196,27.519,26.303$ y 23.637 miles de Qm de trigo, respectivamente. $2{ }^{\circ}$ cuánto trigo se cosechó en cada provincia a lo largo de todo el quinquenio (pero no de año en año) ${ }^{18}$. En otras palabras: ignoramos cuánto trigo se cosechó en cada ar̃o y en cada provincia. De los informes del siguiente lustro sólo sabemos los rendimientos y la producción de cada provincia para todo el período; para el conjunto del país la cosecha ascen-

1884-1887, que presumiblemente tomara en cuenta su información sobre tráficos. Esta investigación constituyó parte de la respuesta al interrogatorio elaborado por la Comisión que redactó el Informe sobre La Crisis Agrícola y Pecuaria. En esta área, y según los datos de la Junta Consultiva Agronómica para 1890-94, se producía casi el 50 por 100 del trigo del país. Por tanto, los 17.724, 12.979, 14.376 y 14.787 miles de Qm recogidos según Norte, implicarían una producción nacional de 35.746, 26.176, 28.994 y 29.823 miles de Qm; es decir, 30.185 miles de Qm de media. Esta producción parece excesiva; baste señalar que la media de las cosechas de 1890 a 1914 fue casi igual: 29.515 miles de Qm. Parece esclarecedor de lo sucedido el hecho de que, según Norte, la productividad de Segovia, Zamora y Salamanca fuera mayor que la de provincias más desarrolladas o con un régimen pluviométrico mucho más favorable, como Barcelona, Vizcaya y Santander. No parece una casualidad que estos rendimientos vengan a justificar la existencia de un medio de transporte que enlaza un Interior "supercerealícola" con una Costa muy deficitaria. Becerro de Bengoa, uno de los informantes orales de dicha Comisión, creía que la afirmación de Norte según la cual había provincias en las que los rendimientos por hectárea superaban los 11 y 13 Hl, era «imposible de admitir». La Crisis Agricola y.Pecuaria, t. III, p. 668, y t. VII, p. 17. Ver también nota 23.

17 Sobre la organización y métodos estadísticos empleados por los primeros organismos oficiales puede consultarse J. I. Muro, F. Nadal y L. Urteaga (1996), y GEHR (1991). ${ }^{18}$ La Crisis Agrícola y Pecuaria (1887-1889), t. VII, p. 579. 
al desplazamiento del consumo del centeno y del maíz hacia el trigo ${ }^{10}$. Éste se vio protegido desde finales de los ochenta por un sistema de cupos a la importación, que posibilitaron la extensión de su cultivo al Alentejo ${ }^{11}$. Pero si las cifras de Lains y Silveira son ciertas, llama la atención que el consumo per cápita haya permanecido estancado desde comienzos de esa década hasta la Primera Guerra Mundial.

Por su desarrollo económico y por la estructura de su producción, el país más próximo a España es Italia. Las importaciones de trigo empezaron a ser verdaderamente cuantiosas a partir de 1885 . El gobierno reaccionó con celeridad, estableciendo aranceles progresivamente más elevados ese mismo año, en 1887 y en 1893. Pero ni la caída de los precios ni su posterior elevación parecen haber afectado al nivel de consumo de trigo hasta los años de cambio de siglo. Así, del estudio de Zaninelli sobre Milán se desprende que, a pesar del crecimiento urbano, la cantidad total de pan, pasta y harina de trigo consumida en 1878-1882 fue casi idéntica a la de $1892-1896^{12}$. Puede que la causa de ello se encuentre en las dificultades por las que atravesó la economía italiana en los años finales de siglo como resultado de varios factores: el retorno de la lira italiana al patrón oro, la guerra comercial con Francia y la crisis de su sistema financiero ${ }^{13}$. Según Ercolani, la tasa de crecimiento anual de la industria manufacturera entre 1874 y 1898 habría sido 0,51 , lo que viene a ser poco más de la cuarta parte de la que hubo entre 1898 y $1913^{14}$.

El gráfico 1 también recoge las cifras de consumo de trigo per cápita en España. Siguiendo el trabajo de Bringas, quien básicamente se apoya en información oficial, he empleado un factor simiente de 1:6,5 -es decir, un 15 por 100 - que posiblemente sea superior al que existía a mediados de siglo; pero que parece el más adecuado para el periodo contemplado ${ }^{15}$. Los años comprendidos entre 1897 y 1901 señalan un incremento notable en el consumo per cápita, similar al que sucede en Italia sólo un lustro más tarde. Podemos aventurar que la diferencia en esos pocos años obedece exclusivamente a los problemas económicos de Italia en la era pre-giolitti. Lo importante es que en uno y otro país el consumo per cápita de trigo

${ }^{10}$ P. Lains (1995), pp. $172-174$ y 195. En efecto, frente a la elevada elasticidad renta del trigo, las del maíz y el centeno son negativas $(-0,21 /-0,23$ y $-034 /-0,37$, respectivamente).

${ }_{11}^{11}$ J. Reis (1993), pp. 35-43.

S. Zaninelli (1974), p. 123.

13 G. Toniolo (1990), pp. 85-97.

${ }_{15}^{14}$ P. Ercolani (1975), pp. 391 y 410.

${ }^{15}$ M. A. Bringas (2000), pp. 116-123. 
dería a 26.190 miles de $Q m{ }^{19}$. Independientemente de la utilidad que se le quiera dar a estos números, parece difícil evaluar la fiabilidad de esta información a partir de datos tan generales. Pero algo se puede hacer.

El cuadro 1 recoge, en miles de Qm, las producciones estimadas por los informes correspondientes a los años 1883 y 1884 . Faltan las cifras de bastantes provincias; pero aún son muchas más las ausencias correspondientes a 1882,1885 y 1886 , motivo por el que no he incluido las pocas de las que dispongo ${ }^{20}$. Cada informe tiene dos columnas debido a que, junto a la cifra del año corriente, se incluía la del precedente. Esta doble contabilidad resulta muy útil, ya que permite cubrir muchas de las lagunas de los informes de un año con los del otro. De esta forma, tenemos las cifras de producción correspondientes a 1883 para 41 de las 47 provincias de la encuesta (las Baleares y las Canarias no se incluyen).

Se podría esperar que, cuando existen ambos informes -en 23 ocasiones--, los dos guarismos de 1883 coincidan. Así sucede quince veces; pero en otras ocho son distintos, de forma que la diferencia entre las producciones de esas provincias asciende a la nada desdeñable cifra de 1.758 miles de Qm. De esas ocho discrepancias, cuatro son muy pequeñas; las otras cuatro son las correspondientes a las provincias de Álava, Cáceres, Ciudad Real y Segovia. Si comparamos esas producciones con las que hubo en los lustros 1882-1886 y 1886-1891, o las posteriores a 1890 , las cifras más bajas, que también son las últimas, aparecen como las más probables. Esto resulta muy evidente en Álava y Segovia, pues de otro modo la cosecha de 1883 habría sido más de tres veces la de 1891-1995. Parece incom-

${ }^{19}$ El GEHR (1988, pp. 51-52) citando la tesis doctoral en curso de uno de sus miembros, Jesús Sanz, cree que la producción de trigo en España en los años 1882-1886 fue la que se desprende de La Crisis Agricola y Pecuaria. En 1887 no hay cifras, pero las que se ofrecen para 1888 y 1889 son muy bajas: 20.800 y 19.300 miles de Qm. Esta información es incompatible con la ofrecida por los avances estadísticos, ya que la media del lustro 1886-1890, de 26.190 miles de Qm, supera la producción de esos años y de 1890 y 1886 ; y por supuesto, no tiene sentido que en 1887 se obtuviese el trigo suficiente para alcanzarla: 46.450 miles de Qm.

Mucho menos crédito merecen las estimaciones de M. K. Bennett (1933, pp. 262 y 272), quien apoyándose en el Corn Trade News, estima la producción de trigo en cada uno de los años del lustro 1885-1889 en 113,5, 86,0, 95,0, 75,9 y 75,0 millones de bushels de 60 libras, respectivamente. Como veremos, semejante evolución contradice la que sería previsible a partir de los datos conocidos de precios, comercio exterior y pluviosidad.

20 Al final del informe de Marcial Prieto (1878, pp. 77-81) sobre la provincia de Burgos aparecen varios estados de la producción y el comercio agrícola por partido judicial, cuyos totales corresponden a los de la nota hallada en el Ministerio de Agricultura sobre la cosecha de 1884. La cuestión es: clas cifras de ese año son meras repeticiones de las de 1878 (u otro año anterior) o se han añadido a la edición del informe impresa, teóricamente, en 1878 ? 
prensible que dos ingenieros agrónomos pudieran incurrir en errores tan grandes, especialmente si tenemos en cuenta que las cifras proporcionadas por el resto de los informes son mucho más acordes. En cambio, el error de Cáceres y Ciudad Real parece fácil de explicar: el cociente entre los dos registros de cosechas es, en cada provincia, de 0,56 y 0,52 , relaciones próximas a la existente entre el hectolitro y la fanega (aproximadamente, $0,555)$. Probablemente la primera cifra venga en esta unidad, y la siguiente en aquélla.

\section{CUADRO 1}

Estimaciones de la producción de trigo en 1882-1886 (Miles Qm)

\begin{tabular}{|c|c|c|c|c|c|c|}
\hline & $\begin{array}{c}\text { Año } p . \\
1882\end{array}$ & $\begin{array}{l}1883 \\
1883\end{array}$ & $\begin{array}{c}\text { Año } p . \\
1883\end{array}$ & $\begin{array}{l}1884 \\
1884\end{array}$ & 1883 & Quinq. \\
\hline Álava ....... & 585,2 & 526,6 & 142,2 & 140,2 & 142,2 & 115,7 \\
\hline Albacete ............. & $1.201,2$ & $1.177,8$ & $1.177,8$ & 883,4 & $1.177,8$ & 499,7 \\
\hline Alicante ............. & 237,4 & 197,9 & & & 197,9 & 242,7 \\
\hline Almería............... & 68,4 & 78,5 & 78,5 & 135,3 & 78,5 & 135,3 \\
\hline Ávila .................. & & & 450,9 & 396,8 & 450,9 & 355,5 \\
\hline Badajoz .............. & $2.088,4$ & $1.893,4$ & & & $1.893,4$ & $1.556,6$ \\
\hline Barcelona ........... & 210,6 & 280,8 & 280,8 & 234,0 & 280,8 & 327,6 \\
\hline Burgos ............... & & & 643,3 & 941,7 & 643,3 & 941,7 \\
\hline Cáceres.............. & 312,0 & 764,4 & 429,4 & 400,5 & 429,4 & 390,3 \\
\hline Cádiz ................. & 219,3 & 781,3 & 770,6 & 701,1 & 770,6 & 634,4 \\
\hline Castellón ........... & 300,3 & 363,5 & 363,5 & 325,2 & 363,5 & 325,2 \\
\hline Ciudad Real ...... & 546,0 & 764,4 & 397,7 & 364,1 & 397,7 & 908,0 \\
\hline Córdoba ............. & 12,9 & 937,4 & & & 937,4 & 937,4 \\
\hline La Coruña.......... & & & & & 14,8 & 14,8 \\
\hline Cuenca ................ & 615,9 & 824,7 & & & 824,7 & $1.542,3$ \\
\hline Gerona ............... & & & & & 91,8 & 91,8 \\
\hline Granada ............. & & & & & 926,5 & 926,5 \\
\hline Guadalajara....... & & & & & 827,0 & 827,0 \\
\hline Guipúzcoa.......... & 123,4 & 114,9 & & & 114,9 & 109,7 \\
\hline Huelva................ & 146,4 & 266,0 & 266,0 & 197,9 & 266,0 & 256,2 \\
\hline Huesca ............... & & & 187,2 & 558,3 & 187,2 & 540,8 \\
\hline Jaén .................... & & 855,0 & 855,0 & & 855,0 & 901,5 \\
\hline 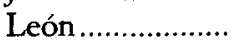 & 367,8 & 441,3 & 441,3 & 511,7 & 441,3 & 472,7 \\
\hline Lérida ................. & & & 148,4 & 402,2 & 148,4 & 475,2 \\
\hline Logroño .............. & & & & & 334,5 & 334,5 \\
\hline Lugo ....................... & 76,8 & 40,7 & & & 40,7 & 27,9 \\
\hline Madrid ................ & 397,0 & 168,1 & 168,1 & 145,8 & 168,1 & 352,9 \\
\hline Málaga................ & & & 352,9 & & 352,9 & 404,1 \\
\hline Murcia................ & 202,8 & 390,0 & 390,0 & 429,0 & 390,0 & 756,7 \\
\hline
\end{tabular}


CUADRO 1 (Cont.)

Estimaciones de la producción de trigo en 1882-1886 (Miles Qm)

\begin{tabular}{|c|c|c|c|c|c|c|}
\hline & $\begin{array}{c}\text { Año } p . \\
1882\end{array}$ & $\begin{array}{l}1883 \\
1883\end{array}$ & $\begin{array}{c}\text { Año p. } \\
1883\end{array}$ & $\begin{array}{l}1884 \\
1884\end{array}$ & 1883 & Quinq. \\
\hline Navarra ............... & 225,4 & 676,2 & 676,2 & 684,8 & 676,2 & 676,2 \\
\hline 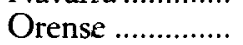 & 21,3 & 17,0 & 17,0 & 21,2 & 17,0 & 20,4 \\
\hline Oviedo .................. & 7,6 & 7,8 & 7,8 & 7,6 & 7,8 & 53,6 \\
\hline Palencia.............. & & & 717,1 & 681,4 & 717,4 & 681,4 \\
\hline Pontevedra........ & 10,1 & 11,9 & 9,3 & 9,3 & 9,3 & 9,3 \\
\hline Salamanca .......... & 897,0 & 982,8 & & & 982,8 & 912,2 \\
\hline Santander........... & 48,4 & 38,7 & 22,6 & 23,1 & 22,6 & 33,6 \\
\hline Segovia ................. & $1.387,3$ & $1.248,6$ & 596,7 & 477,4 & 596,7 & 431,7 \\
\hline Sevilla .................. & 207,9 & $1.247,7$ & & & $1.247,7$ & $1.653,7$ \\
\hline Soria ..................... & 327,6 & 399,8 & 399,8 & 311,0 & 399,8 & $1.310,4$ \\
\hline Tarragona........... & & & & & 114,8 & 114,8 \\
\hline Teruel .................. & & & 566,7 & 503,7 & 566,7 & 536,0 \\
\hline 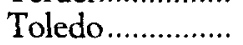 & 551,6 & 851,2 & & & 851,2 & $1.115,7$ \\
\hline Valencia............. & 444,6 & 538,2 & 538,2 & 378,3 & 538,2 & 511,0 \\
\hline Valladolid ........... & $1.247,1$ & $1.454,7$ & & & $1.454,7$ & $1.640,9$ \\
\hline Vizcaya ............... & 62,8 & 64,8 & 64,8 & 72,0 & 64,8 & 72,0 \\
\hline Zamora............... & 429,9 & 630,2 & 639,4 & 676,9 & 639,4 & 708,1 \\
\hline Zaragoza ............ & & & & & 679,4 & 679,4 \\
\hline Total .................... & 13.581 & 18.181 & 10.591 & 10.614 & 22.963 & 25.565 \\
\hline
\end{tabular}

Fuente: AMA cajas 256 y 257. La Crisis Agricola y Pecuaria (1887-1889, t. VI, p. 137).

La cosecha más probable en 1883 es la que aparece en la penúltima columna del cuadro, que ha sido construida con los informes de 1884 (año precedente); sólo cuando éstos no existen, se emplean los de 1883; y cuando tampoco éstos existen, los de todo el quinquenio, que están recogidos en la séptima columna. En total, 22.963 miles de Qm. Sin embargo, La Crisis Agrícola y Pecuaria señala para ese año una cosecha de 26.196 miles de Qm, es decir, más de tres millones de Qm. Es inimaginable que semejante volumen pueda repartirse entre las seis provincias de las que no tenemos datos (en las que, de todos modos, se han tomado los de todo el lustro). La explicación más verosímil es que esa cifra se obtuvo con los primeros informes, que, como hemos visto, ya contenían un error de, al menos, 1.758 miles de Qm.

Como parece que en 1884 se corrigieron las deficiencias de la estadística de 1883, supondré que las cifras posteriores son correctas. Por la misma razón, supondré que los errores de 1883 no son más que la repetición 
de los de 1882, de forma que la cosecha más probable de 1882 sería el 87,7 por $100(22.963 / 26.196)$ de la recogida por La Crisis Agricola y Pecuaria. Pero existe otra buena razón para actuar así: en el cuadro 2 aparecen los precios del trigo entre 1882 y 1886 así como dos estimaciones de su consumo aparente (definido como antes). La primera ha sido construida bajo el supuesto de que las producciones recogidas en La Crisis fueran correctas; y la segunda una vez hechas las correcciones de 1882 y 1883. Si las cifras publicadas fueran ciertas sería difícil explicar cómo dos consumos similares como los de 1882 y 1886 dieron lugar a una diferencia en el precio nacional de más de 5 pesetas por Qm. Del mismo modo, no se entendería que otros dos consumos similares en 1883 y 1884 dieran lugar a diferencias del precio nacional de más de 2 pesetas por Qm. Hecha la corrección, todas las cifras son coherentes.

\section{CUADRO 2}

Precios y consumo aparente de trigo 1882-1886

\begin{tabular}{|c|c|c|c|}
\hline & Precio & Consumo 1 & Consumo \\
\hline $1882 \ldots \ldots \ldots \ldots \ldots \ldots$ & 26,5 & 21.439 & 19.111 \\
\hline ……….......... & 21,5 & 24.601 & 21.853 \\
\hline $1884 \ldots \ldots \ldots \ldots \ldots \ldots$ & 19,6 & 24.080 & 24.080 \\
\hline $1885 \ldots \ldots \ldots \ldots \ldots \ldots \ldots$ & 20,4 & 23.281 & 23.281 \\
\hline $1886 \ldots \ldots \ldots \ldots \ldots \ldots$ & 21,0 & 21.447 & 21.447 \\
\hline
\end{tabular}

Nota: No se incluyen ni las islas Canarias ni Baleares.

FuENTE: La Crisis Agricola y Pecuaria (1887-1889) y N. Sánchez-Albornoz (1975).

Las estimaciones de 1886-1890 han sido cuestionadas por el Grupo de Estudios de Historia Rural, que ha llegado a poner en duda su utilidad ${ }^{21}$. Lo cierto es que los encargados de prepararlas fueron los mismos ingenieros agrónomos que hicieron la nota de cosechas de 1882-1886 o las notas sobre cosechas posteriores a 1890. A diferencia de las anteriores, la estimación de ese quinquenio incluía tanto producciones como rendimientos provinciales; pero no existe ningún desglose anual. No obstante, podemos hacer una estimación razonable de las cosechas de cada año. En primer lugar, sabemos la cuantía de la primera, 1886, por ser la última de las

${ }^{21}$ DGAIC (1891, pp. 595.596); GEHR (1991), p. 30. 
estimadas en la nota de cosechas anterior; falta la producción de las islas Canarias, pero es muy pequeña y podemos estimarla sin demasiado error a partir de los datos de la Junta Consultiva Agronómica. Por otro lado, sabemos la cosecha de 1890 , por ser la primera de las registradas por ese organismo. De esta forma, si a los 130.950 miles de Qm obtenidos en ese lustro ( 26.190 miles de Qm multiplicados por cinco), restamos los 44.448 miles de $Q m$ de esos dos años $(23.637+56,4+20.754,8)$, nos quedan 86.502 miles de Qm "a repartir" en otros tres.

\section{GRÁFICO 2}

Producción y precipitaciones en primavera, 1882-1893

(miles de Qm y mm)

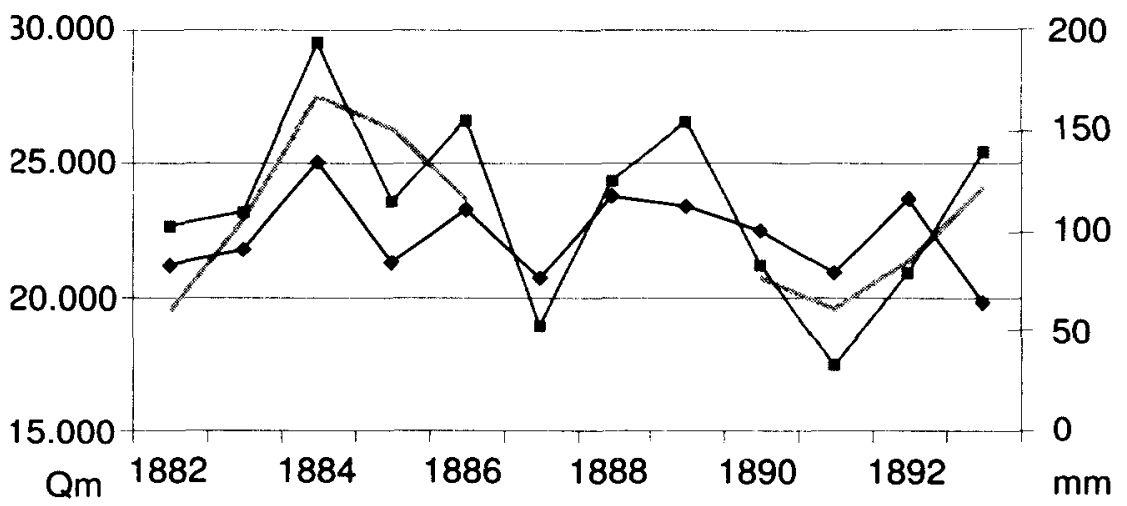

producción $\rightarrow$ pluv. Madrid $\longrightarrow$ pluv. 4 ciudades

El gráfico 2 recoge la producción de trigo entre 1882 y 1886 y entre 1890 y 1893, junto a las lluvias primaverales (abril y mayo) caídas en Madrid y en una media de cuatro capitales "granero": Albacete, Badajoz, Valladolid y Zaragoza. El año 1887 parece haber sido muy seco, mientras que 1888 y 1889 fueron lluviosos. Dadas las condiciones de cultivo del trigo en España, cabría esperar que la cosecha del primer año haya sido escasa, y muy abundantes las de los otros dos. Esta misma evolución es la que describe la red ferroviaria portuguesa del Sur y Sureste - gráfico 3, toneladas de grano transportado-. Pero no así la española —en este caso, y debido a la progresiva ampliación de la red, toneladas de trigo equivalente (trigo 
y harina convertida) por kilómetro de tendido realizado por las compañías MZA y Norte- ${ }^{22}$. En mi opinión, los ferrocarriles portugueses reflejan mejor la coyuntura de la producción española que los propios ferrocarriles españoles porque sus envíos eran más directos (del Alentejo a Lisboa), no se veían afectados por las importaciones o las exportaciones coloniales, y procedían de una región que representaba bien las oscilaciones de la producción de la principal región cerealícola, Castilla.

\section{GRÁFICO 3}

Producción y tráfico ferroviario, 1882-1893

(miles de Qm y miles de TKm)

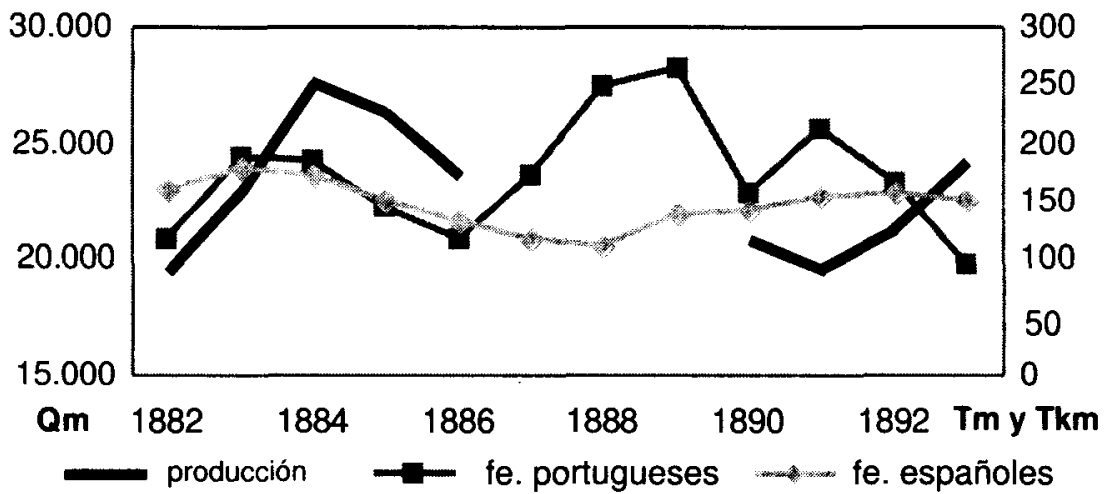

Todavía hay otro motivo para creer que la cosecha de 1887 fue peor que las de 1888 y 1889 . Las importaciones del primer año fueron superiores a las de 1888; y éstas lo fueron a las de 1889. Los precios del trigo de 1887 fueron más altos que los de 1888; que a su vez también lo fueron con respecto a 1889 (que marcó el mínimo de la década). Si los precios caían cuando las importaciones se reducían, sólo cabe suponer que la producción estaba aumentando. En fin, 1887 fue un pésimo año para las exportaciones dirigidas al mercado reservado de Cuba. En definitiva, he empleado los datos pluviométricos de esas cuatro localidades para repartir

${ }^{22}$ Las cifras de comercio exterior de trigos y harinas pueden encontrarse en GEHR (1985, pp. 356-357). Las de tendido y tráfico ferroviario de trigo y harina en R. Anes, (1978, pp. 485-486 y 496-505). Las de tráfico ferroviario portugués de cereales en J. Reis (1993, pp. 44-50). 
esos 86.502 miles de Qm, lo que implica asignar a cada uno de esos años el $24,9,38,3$ y 36,8 por 100 del total. Es decir, en 1887,1888 y 1889 se habrían cosechado 21.554, 33.116 y 31.832 miles de Qm, respectivamente ${ }^{23}$. Si se hubiesen empleado los datos de los ferrocarriles portugueses el reparto habría sido casi idéntico: el 25,1, 36,5 y 38,5 por 100 .

Si detraemos un 15 por 100 de la cosecha como sementera, y añadimos las importaciones netas, estaremos en condiciones de conocer la evolución del consumo en los 20 últimos años del siglo XIx. Ése es el objeto que persigue el gráfico 4, que también recoge los precios y el consumo aparente de trigo en España entre 1882 y 1900 . Hasta 1896, y como cabría esperar, existe una correlación inversa entre una y otra magnitud. Sin embargo, en 1897 el incremento de los precios no se traduce en una reducción del consumo, sino en un aumento. $\mathrm{Al}$ año siguiente, una levísima depreciación conlleva un nuevo y rotundo incremento del consumo. En los tres años siguientes, las variaciones en los precios, más suaves, son paralelas a las del consumo. Esta ruptura en la relación entre ambas variables puede ser una consecuencia del aumento de la producción que siguió al Arancel Cánovas, y que se tradujo en una elevación del precio, de la producción y del autoconsumo; el retardo en siete años puede obedecer a que ese era el plazo mínimo de tiempo para que una coyuntura más favorable fuera tenida como tal por los campesinos.

En fin, la evolución del consumo de trigo per cápita en España sigue la misma pauta que en Italia, pero con cuatro años de anticipación. En España entre 1882 y 1896 se habrían consumido $122,0 \mathrm{kgs} / \mathrm{hab}$., mientras que en 1897-1914 fueron 147,7 kgs/hab.; hubo, pues, un aumento del 21,0 por 100. En Italia, en $1882-1900$ el consumo ascendió a $120,0 \mathrm{kgs} / \mathrm{hab}$., y entre 1901 y 1914 a 161,8 kgs/hab.; es decir, un incremento del 32,4 por 100. En realidad, estos porcentajes deberían ser más próximos, pues las series están construidas con factores simientes constantes, que seguramente fueron menores en los años iniciales; pero dado que la relación española es menor que la italiana (1:6,5 frente a 1:8), un aumento similar habría infravalorado en mayor medida el crecimiento del consumo per cápita en España; lo que, en fin, refuerza el parecido de una y otra tendencia.

${ }^{23}$ Las elevadas producciones de 1888 y 1889 merecen algunas reservas. Si bien son coherentes con el movimiento de los precios, no lo son con el hecho de que las importaciones, aunque decrecientes, existieron. Quizás la estimación de 26.190 miles de Qm de producción media de trigo para todo el lustro haya sido excesiva; aunque también pudo suceder que la oportunidad de la lluvia haya permitido a la agricultura española alcanzar cosechas inesperadas, tal y como sucediera en 1873 y otros años. 


\section{GRÁFICO 4}

Consumo aparente y precio del trigo, 1882-1900

(miles de Qm y ptas $/ \mathrm{Hl}$ )

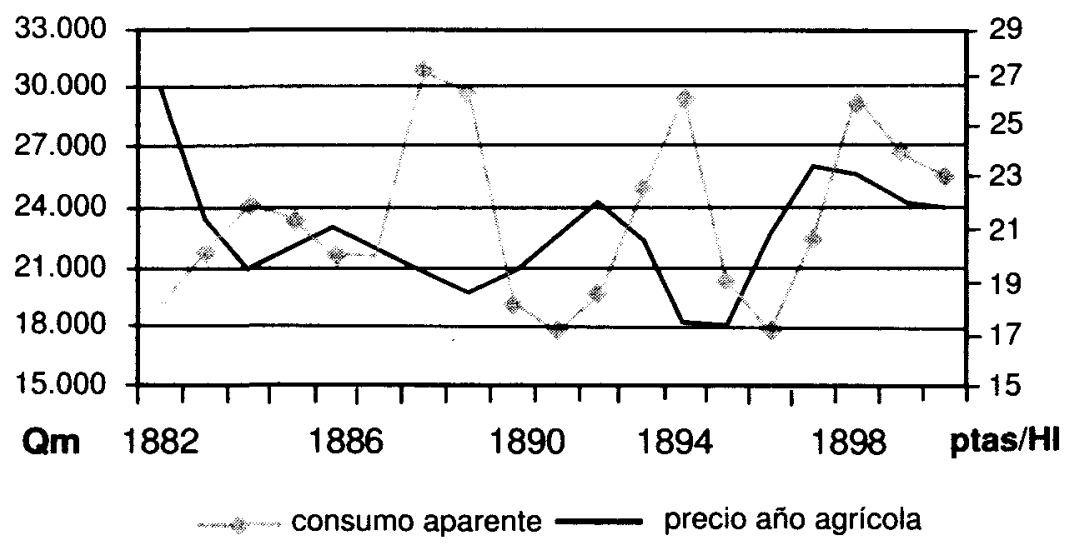

\section{REMONTÁNDONOS HASTA LOS AÑOS SESENTA}

¿La pauta italiana se repite en España en las décadas de los sesenta y setenta? Es decir, ¿el consumo y la producción de esas décadas permanecieron estancados? Tenemos poca base estadística para responder esta pregunta. Fuera de opiniones más o menos disparatadas de expertos nacionales o extranjeros, sólo contamos con dos encuestas que, al menos en teoría, fueron reunidas para todo el país mediante información de ámbito provincial o inferior ${ }^{24}$.

La primera es la nota de cosechas de 1857 elaborada por la Junta Central de Estadística. La cifra de producción de trigo, 13.410 miles de

${ }^{24}$ Por ejemplo, Fermín Caballero en 1867 estimaba la cosecha normal de Espana en 47.691 miles de Qm, cifra que ya fue criticada por G. Tortella (1985, p. 76), y por muchos otros antes que él. También tenemos las estimaciones de Maurice Block para 1871-1875, Mr. Rugle para 1877, y O. J. Broch para 1884, con 51.480 (ccereales comestibles?), 13.304 y 31.200 miles de Qm de trigo (La Crisis Agricola y Pecuaria t. 1, 2." parte, p. 145, y Gaceta Agricola del Ministerio de Fomento, 1877, t. I, pp. 502-503). En fin, J. Sánchez de Toca (1887, p. 160) afirmaba que la producción de trigo venía experimentado una caída constante en los últimos años: en 1871-1875 se habrían cosechado 51.480 miles de Qm (información que debe proceder de Mr. Block), en 1885, 38.220 miles de Qm, y en 1886, 35.880 miles de Qm, respectivamente. Todas estas estimaciones superan la producción media de España para 1890-1914, salvo la de Mr Rugle, que es similar a la de 1857, a la que se supone demasiado pequeña. 
Qm, parece sospechosamente baja. Se suele atribuir tan mal resultado a un clima excepcionalmente adverso, que hubiera provocado la crisis de subsistencia de 1856-1857. Pero lo cierto es que la misma terminó precisamente en 1857 , y la nota de cosechas se refiere expresamente a ese año, y no al de 1856. De hecho, los interrogatorios fueron remitidos a los ayuntamientos en el último trimestre de $1857^{25}$. Por comparación, lo sucedido en Portugal y Francia puede ser ilustrativo. En 1856 en el país luso se recogió algo menos de la mitad de trigo de lo que era habitual; en Francia la cosecha sólo fue mediocre (y vino después de otra que tampoco había sido buena). Sin embargo, en 1857 , y tanto en un país como en el otro, se obtuvieron cosechas excepcionalmente buenas. Sería sorprendente que algo similar no hubiese ocurrido en España. Por tanto, es más razonable suponer que hubo defectos en el método o que, simplemente, muchos ayuntamientos no llegaron a devolver los interrogatorios.

La segunda información es la que recoge La Crisis Agrícola y Pecuaria y sobre cuya elaboración, en principio, sólo sabemos lo que allí mismo se dice:

«Con motivo de la grave crisis de 1868, hízose por el Ministerio de Hacienda un análisis detallado de las cantidades de granos y harinas existentes en la Península e islas adyacentes en los primeros días de julio de aquel año; de los que se calculaba que produciría la cosecha que se estaba recolectando, y de los que se estimaban necesarios para la siembra y el consumo hasta la próxima. De este curioso y útil trabajo tomamos el siguiente cuadro, de las cantidades que se suponían necesarias para el consumo y la siembra en todas las provincias de España».

El cuadro en cuestión aparece a renglón seguido. Las cifras para el trigo, a primera vista coherentes, son las siguientes ${ }^{26}$ :

${ }^{25}$ J. I. Muro, J. Nadal y L. Urteaga (1996), pp. 82-84.

${ }^{26}$ Como norma general, el consumo de trigo en las provincias cerealícolas del interior era más elevado que en las costeras. El centeno era muy cultivado en las comarcas de clima extremo, como el norte de León, por lo que en ellas cabría esperar un consumo menor de trigo; igualmente, la dedicación ganadera de algunas provincias, como Ávila o Huesca, podrían justificar un menor consumo de trigo. Dentro de la costa, el menor consumo correspondía a la Galicia costera y a Asturias. Mayores consumos debía haber en Cantabria - beneficiada por la Ruta de Reinosa- y en Vizcaya y Guipúzcoa - que mantuvieron una importante, aunque minoritaria, producción interna de trigo-. En el Mediterráneo, la comunidad valenciana contaba con dos importantes alternativas al cultivo del trigo, el arroz y el maíz. Almería y Murcia también parecen haberse surtido de estos productos. En cambio, Cádiz y Sevilla eran importantes productoras y consumidoras de trigo. En fin, el consumo de trigo en Barcelona y Madrid debía ser más bajo que en las provincias inmediatas como consecuencia del peso de las capitales y de la mayor renta per cápita. 


\section{CUADRO 3}

Consumo y sementera de trigo en 1868

\begin{tabular}{|c|c|c|c|}
\hline & $\begin{array}{l}\text { Consumo } \\
\text { Miles de } \mathrm{Hl}\end{array}$ & $\begin{array}{c}\text { Siembra } \\
\text { Miles de } H l\end{array}$ & $\begin{array}{c}\text { Cons/hab. } \\
\text { Kgs/hab. }\end{array}$ \\
\hline 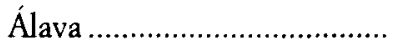 & 214.600 & 40.700 & 142,8 \\
\hline 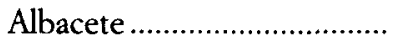 & 525.056 & 110.774 & 153,8 \\
\hline Alicante ................................ & 405.854 & 19.956 & 76,2 \\
\hline 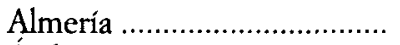 & 272.000 & 44.000 & 53,5 \\
\hline 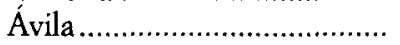 & 187.591 & 50.150 & 62,2 \\
\hline 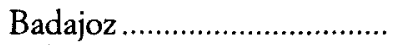 & 1.239 .316 & 209.748 & 191,7 \\
\hline 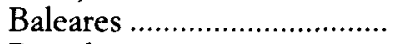 & 445.200 & 73.000 & 105,2 \\
\hline 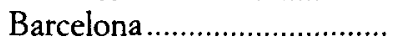 & 1.063 .245 & 25.992 & 104,4 \\
\hline 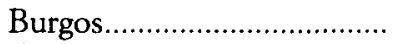 & 799.214 & 177.603 & 145,6 \\
\hline Cáceres .................................. & 739.379 & 86.374 & 167,3 \\
\hline 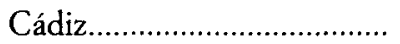 & 1.184 .236 & 152.691 & 196,4 \\
\hline 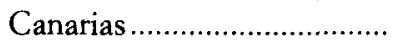 & 103.825 & 18.289 & 25,9 \\
\hline 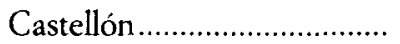 & 399.095 & 41.963 & 102,2 \\
\hline Ciudad Real .......................... & 623.939 & 152.977 & 145,6 \\
\hline 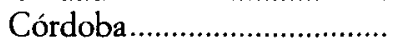 & 567.290 & 111.342 & 96,5 \\
\hline La Coruña............................. & 147.000 & 16.500 & 17,7 \\
\hline 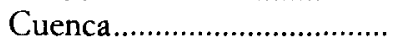 & 636.901 & 305.255 & 111,0 \\
\hline 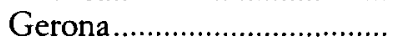 & 296.704 & 52.444 & 62,4 \\
\hline 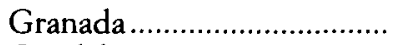 & 569.497 & 72.396 & 84,0 \\
\hline Guadalajara ............................ & 575.000 & 150.000 & 165,6 \\
\hline 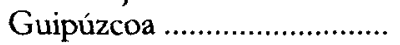 & 233.100 & 17.760 & 103,8 \\
\hline Huelva .................................... & 450.019 & 38.032 & 167,0 \\
\hline 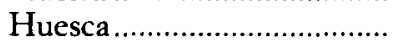 & 332.994 & 107.176 & 69,1 \\
\hline 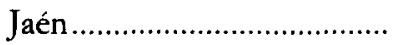 & 888.016 & 126.621 & 154,5 \\
\hline 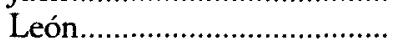 & 405.719 & 114.977 & 64,9 \\
\hline 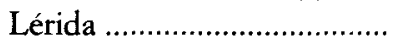 & 645.608 & 47.382 & 157,6 \\
\hline Logroño ................................. & 432.000 & 77.756 & 158,7 \\
\hline 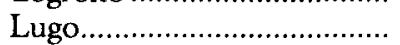 & 60.000 & 11.000 & 9,2 \\
\hline 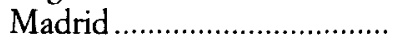 & 1.001 .316 & 108.485 & 130,2 \\
\hline Málaga ................................... & 832.500 & 54.786 & 127,5 \\
\hline 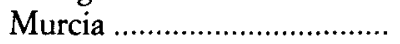 & 580.631 & 87.048 & 92,5 \\
\hline 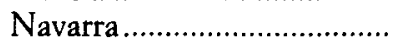 & 839.006 & 134.068 & 182,8 \\
\hline Orense & 20.966 & 2.203 & 3,8 \\
\hline 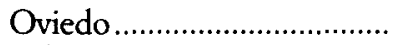 & 208.457 & 14.778 & 27,4 \\
\hline Palencia ............................... & 550.158 & 207.616 & 145,7 \\
\hline Pontevedra............................ & 48.500 & 2.000 & 8,2 \\
\hline 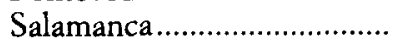 & 647.030 & 50.930 & 169,3 \\
\hline 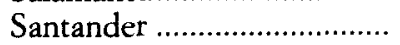 & 221.848 & 10.944 & 73,2 \\
\hline Segovia & 507.458 & 79.266 & 225,0 \\
\hline 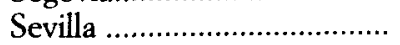 & 1.165 .500 & 194.250 & 156,2 \\
\hline 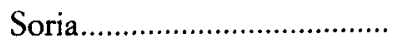 & 308.480 & 205.260 & 53,5 \\
\hline
\end{tabular}




\section{CUADRO 3 (Cont.)}

Consumo y sementera de trigo en 1868

\begin{tabular}{|c|c|c|c|}
\hline & $\begin{array}{c}\text { Consumo } \\
\text { Miles de Hl }\end{array}$ & $\begin{array}{c}\text { Siembra } \\
\text { Miles de Hl }\end{array}$ & $\begin{array}{c}\text { Cons/hab. } \\
\text { Kgs/hab. }\end{array}$ \\
\hline Tarragona.. & 800.000 & 20.000 & 187,0 \\
\hline Terue & 786.587 & 106.453 & 220,7 \\
\hline Toledo..................................... & 1.146 .079 & 351.306 & 186,8 \\
\hline 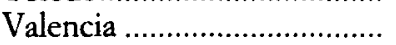 & 721.500 & 24.975 & 84,5 \\
\hline Valladolid............................... & 550.000 & 250.000 & 95,2 \\
\hline 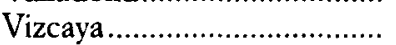 & 127.806 & 555 & 56,6 \\
\hline 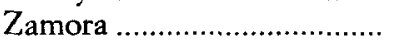 & 674.790 & 69.209 & 189,4 \\
\hline 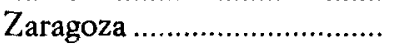 & 1.126 .779 & 320.115 & 160,4 \\
\hline 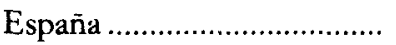 & 27.307 .789 & 4.747 .105 & 109,7 \\
\hline
\end{tabular}

Fuente: La Crisis Agricola y Pecuaria (1887-1889), t. 1, 2. ${ }^{a}$ parte, pp. 144-145.

Del texto se deduciría que fue la urgencia de la crisis lo que impulsó a las autoridades a hacer esta investigación sin otra base que la información que pudo recogerse en unos pocos meses de verano. De haberse actuado así, los resultados merecerían bastantes reservas. Pero posiblemente se disponía de datos bastante más pensados. En el archivo municipal de Segovia, y en el de la Diputación de Álava, existen varios estados sobre la producción, el consumo, la importación y la exportación de cereales, vino y aceite en los años anteriores a 1867. La mera presencia de estas estadísticas, elaboradas por los representantes del gobierno en cada provincia, sugiere que las averiguaciones no fueron tan presurosas. Es más; el detalle es considerable. Por ejemplo, la que disponemos para el partido judicial de Segovia incluye las cifras de los 64 municipios del mismo.

Pero los estados de la Diputación Foral de Álava, por ser provinciales, son más interesantes ${ }^{27}$. Según los mismos, sólo faltan las cifras de tres pueblos, Sabando, Nanclares y Ribera Baja, cuya participación en el total era muy pequeña, tal y como se desprende de las cifras conocidas para 1865 . Entre 1862 y 1867 la producción habría crecido moderadamente, salvo en

${ }^{27}$ El profesor Miguel Ángel Bringas también ha hecho una exhaustiva búsqueda de este tipo de información en archivos municipales y provinciales, pero con resultados negativos. $\mathrm{Si}$ bien hay noticias sobre las cosechas en algunos partidos judiciales, especialmente en los años 1857-1860, ni él ni yo hemos encontrado otro estado que abarque toda una provincia en los años 1862-1867. 
1866, año en el que la cosecha provincial fue mala. El consumo experimentó una tendencia similar, aunque el bache de 1866 es mucho menos pronunciado. Ello fue debido a que la provincia incurrió en un acusado déficit, cuando lo habitual era que hubiese pequeños superávits.

\section{CUADRO 4}

Producción, consumo y comercio de trigo en Álava. Miles de Hl. 1862-1867

\begin{tabular}{|c|c|c|c|c|}
\hline & Producción & Consumo & Import. & Export. \\
\hline $1862 \ldots$ & 154.126 & 164.446 & 93.150 & 95.160 \\
\hline 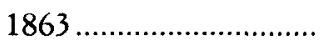 & 150.784 & 164.436 & 105.270 & 104.753 \\
\hline 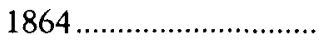 & 155.859 & 164.552 & 100.485 & 106.247 \\
\hline 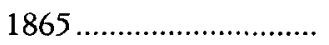 & 154.679 & 171.802 & 94.988 & 84.630 \\
\hline 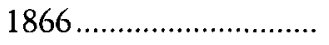 & 126.760 & 165.931 & 90.318 & 61.158 \\
\hline 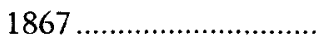 & 164.581 & 171.201 & 92.807 & 102.835 \\
\hline
\end{tabular}

Fuente: Archivo de la Diputación de Álava. Leg. D. 5271-1.

Hay un par de hechos interesantes en este estado. En primer lugar, aparentemente las cifras no encajan. Si suponemos que parte de la producción se dedicaba a la simiente, y que el resto iba dirigido al consumo humano, la suma de esa diferencia (el 70,80 o 90 por 100 de la producción) añadida a las importaciones netas debería ser igual al consumo. En realidad, cabría esperar que fuera algo menor como consecuencia de los almacenamientos, ya que siempre existe un deterioro debido a las mermas de los parásitos; cuando no a las exacciones incontroladas. El problema consiste en que cualquiera que sea el factor simiente que empleemos, esa diferencia es demasiado grande; por ejemplo, con una sementera de $1 / 7$ de la cosecha, la media del consumo de esos seis años habría sido 34.000 $\mathrm{Hl}$ más baja de lo indicado. Por ello, es más razonable suponer que en las cifras de producción no se incluye la simiente. De esta forma, se obtiene una diferencia media de $12.000 \mathrm{Hl}$, quizás excesiva, pero más aceptable.

Ahora bien; si la información de estos estados fue la misma que la empleada para la elaboración de la encuesta de 1868, y cabe suponerlo porque eran los mismos Gobiernos Civiles los encargados de recogerla, sorprende que la cifra de consumo de dicha encuesta sea $214.600 \mathrm{Hl}$, cuando las de aquellos estados rondan los $170.000 \mathrm{Hl}$. Esta diferencia puede explicarse si suponemos que en la estadística del Ministerio las cifras 
de consumo incluían la simiente, que asciende, según el mismo estado, a $40.700 \mathrm{Hl}^{28}$. Pero hay otro motivo más para suponerlo así. Dado que, en años normales, el saldo comercial de trigo representaba una parte muy pequeña - y positiva - de la producción, podemos suponer que la relación entre consumo y simiente se aproxima - por defecto- al factor simiente. Si las cifras de consumo de la encuesta de 1868 no incluyen la simiente, este factor sería muy próximo a $1: 7$, que es un poco mayor al que hemos manejado, con bastantes precauciones, para finales de siglo; pero que resulta inverosímil para la década de los sesenta. Baste señalar que en Francia en 1852 era un poco mayor a 1:6, siendo ésta una nación con un régimen pluviométrico mucho más favorable, y con tierras mucho más feraces ${ }^{29}$. En cambio, si se incluye, el factor simiente sería un poco inferior a esa relación, lo que resulta mucho más creíble.

Por tanto, hay buenas razones para suponer que el consumo al que se alude en la estadística del Ministerio de Fomento incluía la simiente; lo cual, por cierto, no es refutado, aunque tampoco confirmado, por el texto de La Crisis ${ }^{30}$. La pregunta parece obligada: ¿por qué esas ambigüedades? Lo que propuso la Subcomisión de Cereales que redactó las actas de las sesiones que he reproducido fue la protección del trigo que se plasmaría poco después en el Arancel Cánovas. Dicha protección se justificaría más fácilmente en un país muy cerealícola que en otro con una variada producción agrícola. Es significativo que los informantes proclives a la protección sobrevaloraban las cosechas de trigo del país, mientras que las pocas voces partidarias del Librecambio cuestionaban la capacidad

${ }^{28}$ Esto supone aceptar un factor simiente de 1:4,3 para el trigo (174.000/40.700). Por otro lado, la Junta de Agricultores de la Provincia de Álava (legajo D.1836-8) reconoce, con muchas reservas, que en el Distrito Municipal de Vitoria en 1871 era de $1: 7$, lo que resultaría coherente con un factor simiente de 1:6 para toda España. Nótese que en el área colindante con la única ciudad de la provincia, en una comarca especialmente fértil y húmeda, el factor simiente no era particularmente alto. La producción calculada para ese año en ese distrito era de $28.227 \mathrm{HL}$.

${ }^{29}$ H. D. Clout (1983), p. 75. Ver también M. Demonet (1985), pp. 91.95.

${ }^{30}$ Hay otro indicio en el mismo sentido. En el informe elaborado por el ingeniero agrícola de la provincia de Logroño, don Antonio Tadeo Delgado (1876, pp. 77-81), se indica que la producción de trigo del quinquenio 1862-1866, los mismos años que los del informe de Álava, fue de 343.553 miles de Hl. Por tanto, los 77.756 miles de $\mathrm{Hl}$ requeridos por la sementera según la encuesta de 1868 implicarían un rendimiento de 1:4,2, lo que parece verosímil en una provincia seca y montuosa como La Rioja, pero que resulta mucho más bajo del supuesto por el informante, de 1:6. En todo caso, el consumo recogido en la encuesta, 432.000 miles de $\mathrm{Hl}$, es muy superior a esa producción. Salvo que supongamos un déficit crónico de trigo de la provincia, lo más sensato es creer que la cifra de consumo incluye la sementera. La diferencia entre una y otra, 354.244 miles de Qm, es bastante similar a la presentada por Delgado. 
del campo español para alimentar a toda la población, al menos de forma regular. Así se entiende la profusión de noticias poco fidedignas sobre la producción triguera a las que hemos aludido, y que con una única excepción, dan cifras increíblemente elevadas. Quizás también ese "estado de ánimo" explique los graves errores en la estimación de la cosecha de 1883 .

Aceptando que las cifras de consumo del cuadro 3 incluyen la simiente, y tomando como población en 1868 la media de las expresadas por los censos de 1857 y 1877, el consumo per cápita de trigo en España habría sido de 109,4 kilogramos anuales. La estadística de Álava revela que en 1866, y como consecuencia de la mala cosecha, se produjo una leve caída en el consumo. Podemos suponer que la pésima cosecha de 1868 haya tenido un efecto similar o mayor en todo el país. Dado que entre 1882 y 1896 el consumo de trigo per cápita fue de 122,0 kilogramos anuales, entiendo que puede aceptarse la hipótesis de que con anterioridad a 1896 no hubo variaciones significativas en dicha magnitud.

\section{HIPÓTESIS SOBRE EL CONSUMO Y LA PRODUCCIÓN DE TRIGO EN ESPAÑA}

Así pues, en el último tercio del siglo XIX España e Italia parecen haber seguido un patrón común en el consumo y la producción de trigo. Pero esta circunstancia no sólo no cierra la cuestión, sino que abre nuevos interrogantes, ya que las condiciones bajo las cuales se desenvolvió la agricultura cerealícola fueron muy diferentes en uno y otro país. Y ello, entre otros motivos, porque en España la oferta de suelo agrícola se vio muy alterada por el proceso desamortizador. No disponemos de cifras exactas, pero es muy posible que entre 1855 y el fin de siglo se enajenase una superficie equivalente al 10 por 100 del territorio nacional. La mayor parte de esas tierras no estaban cultivadas; y tampoco se puede afirmar que, después de vendidas, se roturasen; ni que, las que lo fueran, se cultivasen con trigo. Sobre lo que no hay ninguna duda es que el proceso de ventas se prolongó a lo largo de toda la segunda mitad del siglo, por lo que sus efectos deben ser contemplados a largo plazo. Ahora bien; si existió una oferta abundante de tierras durante todo el Sexenio Democrático y la Restauración, ¿́por qué ésta no posibilitó un incremento de la producción que redundara en un aumento de los niveles de consumo per cápita?

El período 1868-1896 puede dividirse en dos de forma muy nítida. Hasta 1882 las condiciones económicas bajo las que se desarrolló la agricultura cerealícola fueron relativamente buenas. Aunque desde 1867 se 
levantó la prohibición a las importaciones de trigo y harina, el régimen arancelario fue moderadamente proteccionista, con tipos del 10 al 20 por 100 sobre el precio en la costa, lo que permitió al cereal español mantener su precio ${ }^{31}$. Con una gran oferta de tierras cabría esperar una producción en auge; pero la lluvia no vino. El cuadro 5 recoge las precipitaciones primaverales —abril y mayo- caídas en Albacete, Badajoz, Madrid, Sevilla, Valladolid y Zaragoza desde 1868 hasta 1980. Del mismo se desprende que, salvo en el Valle del Ebro, el período 1868-1881 fue uno de los más secos de la historia de España ${ }^{32}$. Es probable que la explotación de tierras de mala calidad, como debían ser las de los comunales desamortizados, se haya visto truncada por la falta de precipitaciones. En este tipo de espacios - terrenos calizos, en pendiente, etc.- la oportunidad de la lluvia era esencial para obtener cosechas regulares.

\section{CUADRO 5}

Lluvias primaverales entre 1868 y $1980 . \mathrm{mm}$.

\begin{tabular}{|c|c|c|c|c|c|}
\hline & $1868-1881$ & $1882-1895$ & $1896-1930$ & $1931-1960$ & $1961-1980$ \\
\hline Albacete & 87,0 & 95,0 & 83,0 & 87,8 & 96,6 \\
\hline 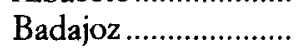 & 72,8 & 129,7 & 87,7 & 78,8 & \\
\hline 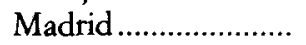 & 69,1 & 110,7 & 74,9 & 89,1 & 89,4 \\
\hline Sevilla ........................... & 70,8 & 102,6 & 86,2 & 97,7 & 90,7 \\
\hline Valladolid...................... & 55,3 & 81,3 & 74,5 & 72,1 & 88,3 \\
\hline Zaragoza .................... & 77,2 & 68,0 & 55,9 & 78,8 & 73,3 \\
\hline
\end{tabular}

FuENTE: SMN (1943), Roldán Fernández, A. (1985, 1987, 1988) y ANE (1982).

Desde el punto de vista meteorológico, el período 1882-1896 tiene características prácticamente opuestas al anterior. Tal y como se aprecia en el mismo cuadro, la lluvia fue abundante; pero esta vez los precios no acompanaron la recuperación ${ }^{33}$. La arribada de trigos norteamericanos cultivados en el Medio Oeste, y llegados a Europa por medio de las nuevas

${ }^{31}$ Fuente: GEHR (1985), p. 348.

32 Esta excepción es bastante previsible. La presencia del Sistema Ibérico provoca una. alternancia pluviométrica entre el Este y el Oeste de la Península. Años secos en Castilla suelen ser lluviosos en Aragón, y viceversa.

${ }^{33}$ CDemasiado lluvioso? Hubo sequías en 1882, 1887 y 1890, por lo que, si la media siguió siendo elevada, necesariamente tuvo que llover mucho en los otros años. Y un exceso de precipitaciones en mayo, cuando el trigo ya ha espigado, puede ser contraproducente. 
líneas férreas, hundió los mercados; así, entre 1882 y 1886 el precio del grano en el Reino Unido cayó un 31,2 por $100^{34}$. No hubo una respuesta única a la crisis. Por ejemplo, el estudio de cinco haciendas toscanas efectuado por Galassi revela que los propietarios reaccionaron dedicando las tierras menos aptas a otros cultivos, pero también incrementando la productividad de aquellas en las que se siguió cultivando cereal ${ }^{35}$. No debió suceder lo mismo en Portugal, donde, según Reis, la modernización estaba ligada al movimiento combinado del precios a la baja de los abonos químicos, y al alza del trigo ${ }^{36}$. En el secano español, donde el empleo de estos abonos era extraño, posiblemente todo lo que se hizo fue abandonar los espacios marginales ${ }^{37}$. Debido a que el mercado del aceite estaba pasando por dificultades en sus mercados de salida, la única alternativa comercial viable a la explotación de muchas tierras de reciente ocupación era el viñedo ${ }^{38}$; aunque no pasarían muchos años antes de que esta opción también desapareciera como consecuencia de la superación de la filoxera en Francia. No obstante, tampoco cabe pensar en un abandono masivo de tierras. $\mathrm{Al}$ fin y al cabo, en muchas de ellas la justificación del cultivo se encontraba en el autoconsumo ${ }^{39}$.

Ahora bien; si como consecuencia de las importaciones de trigo la producción se mantuvo bajo mínimos entre 1882 y 1896, ¿̇por qué esas mismas importaciones no compensaron la caída de la producción? Podemos sugerir una respuesta con razonamientos similares a los expuestos al principio de estas páginas: $1 .^{\circ} \mathrm{La}$ demanda de trigo tendría una elevada elasticidad renta para los campesinos productores, por lo que una caída de los ingresos habría provocado una caída del consumo. $2{ }^{\circ}$ El trigo tendría una baja elasticidad de la demanda entre los consumidores no productores, por lo que un descenso de su precio no generaría un aumento significativo del consumo.

No sabemos cómo evolucionó la renta de los distintos grupos socioprofesionales del país; pero hay muchos indicios acerca de cómo se modificó

${ }^{34}$ B. R. Mitchell y P. Deane (1962), p. 489.

35 F. Galassi (1986), pp. 311-316.

${ }^{36} \mathrm{~J}$. Reis (1993), pp. 75-79.

37 J. Simpson (1995), pp. 109-125; D. Gallego (1986), pp. 177-184.

38 J. F. Zambrana (1987), pp. 53-69 y 203-213.

39 Precisamente ésta es una de las cuestiones abordadas en el interrogatorio que da base a la información de La Crisis Agricola y Pecuaria (1887-1889). Pero la conclusión obtenida de las respuestas dadas, y que suscribe la propia Comisión, es que, salvo algunos casos puntuales, éste no fue un fenómeno generalizado. De hecho, sabemos que la mayor parte de la expansión vinícola de esos años tuvo lugar en las regiones mediterráneas, cuya dedicación cerealícola era menor que las del interior. Según T. Carnero (1980, pp. 57-69 y $97-98$ ) el 74,6 por 100 de las exportaciones de vino común de esos años salieron de Cataluña y Valencia. 
en cada una de las regiones en las que estos grupos eran dominantes. La pauta seguida por las migraciones interiores, la comparación del crecimiento de las ciudades, la localización de los primeros núcleos industriales y mineros, la de la agricultura de exportación, las ventas de maquinaria agrícola y abonos químicos, y mil hechos más, prueban que el crecimiento de la renta en las regiones costeras fue mayor que en las del interior. Sin embargo, no parece que haya habido grandes cambios en las pautas de consumo de trigo. Las principales provincias consumidoras en 1868, las del interior, eran las mismas en 1895 . Si bien se había conquistado el mercado norteño por la sustitución del maíz por el trigo, también había crecido el consumo en los valles del Ebro y Duero. Es más: en términos absolutos ese crecimiento parece haber sido muy superior a aquél ${ }^{40}$. Por tanto, cabe suponer que en el interior -es decir, entre los campesinos productores-, la elasticidad renta era elevada.

Podemos tratar la elasticidad demanda-precio con más refinamiento. Persson la calcula como el cociente entre las desviaciones estándar de los incrementos anuales de las cantidades consumidas per cápita y las de sus precios, en series desprovistas de tendencia ${ }^{41}$. Si aquéllas fueran mayores a éstas, la elasticidad de la demanda sería mayor a la unidad, lo que es decir que la demanda era elástica: grandes variaciones en las cantidades consumidas sólo suponen pequeñas variaciones en los precios. Lo contrario sucedería con curvas de demanda inelásticas. El procedimiento no deja de ser una aproximación, pues implica asumir que existe una correlación perfecta entre ambas variables. Además, al no incluir el efecto de los almacenamientos y el comercio exterior existe una sobrestimación del resultado (pero también una infraestimación por el efecto del factor simiente). Por razones documentales obvias, es muy difícil estimar la desviación estándar del consumo per cápita a escala provincial, incluso con posterioridad a 1890. Además, la equiparación del consumo aparente (producción menos sementera más importaciones netas) con la variable consumo puede recoger el efecto generado por el comercio; pero no el de los almacenamientos a largo plazo; precisamente ello explica el aspecto de "sierra" del gráfico 4.

40 J. Sanz (1990, pp. 303-310). De la comparación de las cifras obtenidas por la Dirección General de Aduanas en 1890-1894 con las del Ministerio de Fomento de 1868 se desprende que los mayores incrementos relativos en el consumo de trigo tuvieron lugar en Galicia, Aragón y Castilla y León. Pero con relación al trigo total consumido, estas dos últimas regiones destacan sobremanera.

${ }^{41}$ K. G. Persson (1996), pp. 695-696. 
Un procedimiento análogo al descrito consiste en relacionar las medias de las variaciones anuales y absolutas de las cantidades consumidas y de los precios ${ }^{42}$. Pues bien; para el período 1890-1914 el valor de dicho estadístico en el consumo fue igual a 12,5 por 100; por supuesto, en el período anterior a 1890 sería mayor, al incluir crisis agrícolas como la de 1868. Las medias de las variaciones absolutas de los precios agrícolas entre 1860 y 1883 , en las regiones costeras, en el interior, y en todo el país, rondaron el 8 por $100(7,9,8,2$ y 8,4 por 100$)$. Por tanto, el cociente entre unas y otras sería $1,5 / 1,6$. Aunque probablemente estos valores sólo sean aproximaciones por exceso al "verdadero" valor de la elasticidad de la demanda, parece obvio que no se puede hablar de una demanda rígida ni en los consumidores productores, ni en los no-productores. Lo cual debe atribuirse a los efectos del comercio interior y exterior; a la capacidad de los mayoristas para absorber las oscilaciones del mercado con sus excedentes; y a la existencia de alternativas alimenticias de consumo (patatas, maíz, arroz...), especialmente en las regiones costeras.

En definitiva, el estancamiento del consumo puede ser explicado por el efecto renta; pero no por la rigidez de la demanda. Si la caída de los precios de los años 80 no generó un significativo incremento del consumo fue debido a que esa misma caída hizo perder capacidad adquisitiva a muchas familias campesinas, que tuvieron que desplazar parte de su consumo de trigo hacia opciones alimenticias menos atractivas. Por eso mismo, lo que podemos suponer acerca de las consecuencias del Arancel Cánovas sobre la economía española es que mejoró las condiciones de vida de esos trabajadores, permitiendo un aumento de la producción y el consumo de trigo.

\section{CONCLUSIONES}

Las diferencias existentes entre la evolución del consumo per cápita de trigo en Italia, Francia y Portugal son grandes; pero también hay rasgos comunes: en los tres países el consumo de trigo a comienzos del siglo $\mathrm{xX}$ era mayor que a mediados del siglo XIX. Por tanto, parece razonable hacer alguna suposición similar en el caso español. Los datos proporcionados por la Junta General de Agricultura desde 1890 sugieren que el modelo italiano

42 La utilización de desviaciones absolutas (o promedio) en lugar de desviaciones estándar se justifica porque, al no elevar al cuadrado las diferencias con la media, se evita el efecto distorsionador generado por los valores extremos. La tendencia se ha eliminado aplicando medias móviles de nueve años. 
se ajusta al español mejor que los otros dos. Ello es coherente con los presumibles niveles de renta y la estructura del consumo de ambas naciones. La información estadística que hemos rescatado también confirma esa evolución. Las cifras pueden contener errores más o menos grandes, pero ninguna de ellas permite apartarse significativamente de los niveles de consumo de 1890-1896. Incluso la estadística de 1868, con todos sus problemas, confirma esa tendencia. Da la impresión de que cuando los interrogatorios se completaron los resultados fueron aceptables. La confusión parece haber nacido del tratamiento final o de su lectura última. Entonces, como ahora con las encuestas pre-electorales, lo importante no era lo que decían los números, sino lo que el lector quería ver en ellos.

\section{APÉNDICE}

El siguiente cuadro recoge las estimaciones de la producción y el consumo aparente de trigo bajo el supuesto de que se dedicara a la simiente el 15 por 100 de la cosecha. En las cifras anteriores a 1887 no se incluye la producción de las islas Canarias y Baleares. En las cifras de 1887, 1888 y 1889 está incluida la de Baleares. Y sólo la de 1890 se refiere a todo el país. La producción de las islas Canarias era muy pequeña - 56,4 miles de Qm en 1890-94-; pero la de las Baleares, sin ser grande, tenía cierto peso - 371,2 miles de Qm en dicho lustro-. Por tanto, había que añadir unos 425 miles de Qm a las cifras de los primeros años para conocer la verdadera producción nacional.

Estimaciones de la producción y el consumo de trigo en la España continental. Miles de Qm

\begin{tabular}{clrl}
\hline \multicolumn{1}{c}{ Año } & Producción & \multicolumn{1}{c}{$\begin{array}{c}\text { Saldo } \\
\text { comercial }\end{array}$} & $\begin{array}{c}\text { Consumo } \\
\text { aparente }\end{array}$ \\
\hline $1882 \ldots \ldots \ldots \ldots \ldots$ & 19.459 & -2.570 & 19.111 \\
$1883 \ldots \ldots \ldots \ldots \ldots$ & 22.963 & -2.335 & 21.853 \\
$1884 \ldots \ldots \ldots \ldots \ldots$ & 27.519 & -689 & 24.080 \\
$1885 \ldots \ldots \ldots \ldots \ldots$. & 26.303 & -924 & 23.281 \\
$1886 \ldots \ldots \ldots \ldots \ldots$ & 23.637 & -1.356 & 21.447 \\
$1887 \ldots \ldots \ldots \ldots \ldots$ & $21.554^{*}$ & -3.260 & 21.582 \\
$1888 \ldots \ldots \ldots \ldots \ldots$ & $33.116^{*}$ & -2.684 & 30.833 \\
$1889 \ldots \ldots \ldots \ldots \ldots$ & $31.832^{*}$ & -1.555 & 29.704 \\
$1890 \ldots \ldots \ldots \ldots \ldots$ & $20.754^{* *}$ & -1.508 & 19.149 \\
\hline
\end{tabular}

* Incluye Baleares, pero no Canarias.

** Incluye Baleares y Canarias.

FuENTE: AMA, Cajas 256 y 257, La Crisis Agrícola y Pecuaria (1887-1889), DGAIC (1891, pp. 595-596) y GEHR (1985, pp. 356 y 357). 


\section{BIBLIOGRAFIA}

ANUARIO NACIONAL DE ESTADISTICA, ANE (1982).

Archivo de la Diputación de ÁlaAva. Legajos D. 5271-1 y D.1836-8.

Archivo del Ministerio de. Agricultura, AMA, Cajas 256 y 257.

ANES, R. (1978): «Relaciones entre el ferrocarril y la economía española (1865-1935)», en ARTOLA, M. (dir.): Los ferrocarriles en España. 1844-1943, vol. II, Madrid, Banco de España, pp. 357-529.

Bennetr, M. K. (1933): «World Wheat Crops, 1885-1932», Wheat Studies, Stanford University, IX, pp. 239-274.

- (1935): «Per Capita Wheat Consumption in Western Europe», Wheat Studies, Stanford University, XI, pp. 255.305.

BRingas, M. A. (2000): La productividad de los factores en la agricultura española (1752-1935), Banco de España.

CARNERO, T. (1980): Expansión vinicola y atraso agrario 1870-1900, Madrid, Ministerio de Agricultura.

Clout, H. D. (1983): The land of France 1815-1914, London, George Allen \& Unwin.

- La Crisis Agricola y Pecuaria (1887-89), Biblioteca Nacional.

DELGADO, A. T. (1876): Memoria sobre el estado de la agricultura e industrias derivadas de la provincia de Logroño, Logroño, Imprenta de Federico Sanz.

Demonet, M. (1985): Tableau de l'Agriculture Française au milieu du $19^{\circ}$ siècle. L'enquête de 1852, Paris, École des Hautes Études en Sciencies Sociales.

Dirección General de Agricultura, Industria y Comercio, DGAIC (1891): Avance estadístico del cultivo cereal y leguminosas asociados en España, quinquenio de 1886 a 1890, ambos inclusive, 3 vols., Madrid.

Ercolani, P. (1975): «Documentazione statistica di base», en FuA, G. (dir.), Lo sviluppo economico in Italia, 3 vols., Milano, Franco Agneli, pp. 389-472.

FEDERICO, G. (1982): «Per una valutazione critica delle statistiche della produzione agricola italiana dopo l'Unità (1860-1913)», Società e Storia, 5, pp. 87-130.

GACETA AgRICOLA DEL MINISTERIO DE FOMENTO, 1877, t. I, Biblioteca Nacional.

GALASSI, F. (1986): «Stasi e sviluppo nell'agricoltura toscana, 1870-1914: primi resultati di uno studio aziendale», Rivista di storia economica, 3, pp. 304-337.

GALLEGO, D. (1986): «Transformaciones técnicas de la agricultura española en el primer tercio del siglo XX», en Garrabou, R.; Barciela, C., y Jiménez, J. L. (eds.): Historia agraria de la España contemporánea, vol. III, Barcelona, Crítica, pp. $171-229$.

Grupo de Estudios de Historia RuRal, GEHR (1985): «Los precios del trigo y la cebada», en Garrabou, R., y SANZ, J. (eds.): Historia agraria de la España contemporánea, vol. II, Barcelona, Crítica, pp. 321-368.

- (1988): «La crisis agrícola en Castilla la Vieja y Andalucía: los casos del trigo y el olivar», en GARRABOU, R. (ed.): La crisis agraria de fines del siglo XIX, Barcelona, Crítica.

- (1991): Estadísticas Históricas de la Producción Agraria Española, Madrid, Ministerio de Agricultura, Pesca y Alimentación.

Justino, D. (1988-89): A formação do espaço económico nacional, 2 vols., Lisboa, Vega. 
LaINS, P. (1990): «A Evolução da Agricoltura e da Indústria em Portugal (1850-1913). Uma interpretação Quantitativa», História Económica, 1, Banco de Portugal.

LaINs, P. (1995): A Economia Portuguesa no século XIX, Lisboa, Imprensa Nacional da Casa da Moeda.

Lains, P., y Silveira, P. (1998): «Estatística e produçāo agrícola em Portugal, 1848-1914», Análise Social, 149.

LÉVY-Leboyer, M., y Bourguignon, F. (1990): The French economy in the nineteenth century, Cambridge, Cambridge University Press.

Mrtchell, B. R., y Deane, P. (1962): Abstract of British Historical Statistics, Cambridge University Press.

Mrtchell, B. R. (1992): International Historical Statistics Europe 1750-1988, Hong Kong, Stockton Press.

Muro, J. I.; NADAL, F., y URTEAGA, L. (1996): «Los orígenes del Instituto Geográfico y Estadístico», Albor, 609-610, pp. 59-91.

Percosol.ldo, G. (1994): Agricoltura e industria nell'Italia unita, Roma, Laterza.

PERSSON, K. G. (1996): «The seven lean years, elasticity traps, and intervention in grain markets in pre-industrial Europe», Economic History Review, XIIX, 4, pp. 692-714.

PRIETO, M. (1878): Informe sobre el estado actual de la agricultura en la provincia de Burgos, Burgos, Imprenta de la Viuda e Hijo de T. Santamaría.

ReIs, J. (1993): O Atraso Económico Português em Perspectiva Histórica, Lisboa, Imprensa Nacional Casa da Moeda.

RoldÁn, A.: Notas sobre el clima de la provincia de: (1985) Madrid (1985) Sevilla (1985) Valladolid (1985) Zaragoza (1987) Badajoz (1988) Albacete. Madrid, Instituto Nacional de Meteorología.

SÁnCHEZ-AlBornoz, N. (1975): Los precios agrícolas durante la segunda mitad del siglo XIX, Madrid, Banco de España.

SÁNCHEZ DE TOCA, J. (1887): La crisis agraria europea y sus remedios en España, Madrid.

SANZ, J. (1990): «La crisis triguera finisecular», en Garcí Delgado, J. L. (ed.): La España de la Restauración, Madrid, Siglo XXI, pp. 265-310.

Servicio Meteorológico Nacional, SMN (1943): Las series más largas de observaciones pluviométricas en la Peninsula Ibérica, Madrid.

Simpson, J. (1995): Spanish Agriculture. The long siesta, 1765-1965, Cambridge, Cambridge University Press.

SMITH, M. S. (1980): Tariff reform in France 1860-1900, Ithaca and London, Cornell University Press.

Toniolo, G. (1990): An Economic History of Liberal Italy 1850-1918, London, Routledge.

TORTELLA, G. (1986): «Producción y productividad agraria 1830-1930», en La modernización económica de España 1830-1930, Madrid, Alianza, pp. 63-88.

Zambrana, J. F. (1987): Crisis y modernización del olivar, Madrid, Ministerio de Agricultura.

Zaninelui, S. (1974): I consumi a Milano nell'Ottocento, Roma, Edindustria Editoriale. 